\title{
Formação inicial de professores de química: a utilização dos relatórios de observação de aulas como instrumentos de pesquisa
}

\section{Initial formation of teachers of chemistry: the use of the reports of observation of classes as instruments of research}

\author{
Fabiele Cristiane Dias Broietti ${ }^{1}$; Sônia Regina Giancoli Barreto ${ }^{2}$
}

\begin{abstract}
Resumo
Neste estudo, foram utilizados os relatórios de observação de aulas como ferramenta de pesquisa, servindo de instrumento para se investigar sobre formação inicial de professores de química. O estudo consistiu em analisar 12 relatórios, elaborados por alunos de um curso de Licenciatura em Química e discutir por meio das narrativas dos alunos, tópicos referentes a estrutura escolar e ao ensino de química. As narrativas se mostraram instrumentos importantes a serem analisadas a fim de se examinar a formação inicial. Este trabalho confirmou e ressaltou a relevância do estágio de observação na formação do licenciando como um momento de pesquisa e reflexão da prática docente.

Palavras-chave: Formação inicial. Estágio supervisionado. Química.
\end{abstract}

\begin{abstract}
In this study, we used the reports of classroom observation as a research tool, serving as a tool for research on initial teacher training in chemistry. The study analyzed 12 reports prepared by students of Degree in Chemistry and to discuss through the narratives of students, topics related to school structure and teaching of chemistry. The narratives have proved important implements to be analyzed to examine the initial formation. This work confirmed and underscored the relevance of the observation stage in the formation of teaching as a moment of research and reflection of teaching practice.
\end{abstract}

Keywords: Initial formation. Supervised stage. Chemistry.

\section{Introdução}

O tema formação de professores, de um modo geral e de química mais especificamente, tem sido muito debatido perpassando por aspectos variados, que vão desde as necessidades formativas, a análise crítica da formação atual à propostas de reestruturação curriculares (MALDANER, 2000; CARVALHO; GIL-PÉREZ, 2003; GALIAZZI, 2003; FRANCISCO JUNIOR; PETERNELE; YAMASHITA, 2009; LORENCINI, 2009).

No sistema de ensino superior, são os cursos de licenciatura as estâncias oficias referentes à formação inicial de professores, no entanto, sabese que a formação profissional do professor não se inicia apenas no curso de licenciatura nem se limita a ele, mas se constrói ao longo de toda a vida.

Os currículos dos cursos de licenciatura devem contemplar a parte de conteúdos, relativa aos conhecimentos específicos da área e também, a parte pedagógica, relativa ao preparo do licenciando para o magistério. Contudo, a interação entre essas duas partes não tem sido muito harmoniosa,

Departamento de Química da Universidade Estadual de Londrina. Email: fabieledias@uel.br.

2 Departamento de Química da Universidade Estadual de Londrina. Email: giancoli@uel.br. 
uma vez que, no Brasil, tradicionalmente, os currículos de licenciatura foram concebidos como meros apêndices aos currículos de bacharelado (CANDAU, 1987). Ao invés de uma mescla/ intersecção entre as duas partes, o que se percebe na verdade é uma tentativa, um pouco frustrada, de uma soma de conhecimentos de conteúdos específicos e conteúdos pedagógicos.

Há consenso de que esse modelo, perdurado durante muitos anos, pautado na racionalidade técnica e denominado de "3 + 1", em que disciplinas de conteúdo específico constituem o eixo da formação nos três primeiros anos do curso, e as disciplinas de natureza pedagógica, são ministradas com duração de um ano, é altamente insuficiente e não provê de forma adequada, a necessidade de unificar conhecimentos de caráter pedagógico e específico (GALIAZZI, 2003).

O modelo da racionalidade técnica, surgido com os avanços tecnológicos educacionais, tem se mantido até hoje como perspectiva para a formação de professores. Esta perspectiva propõe dar ao ensino o status de ciência aplicada, no qual a qualidade desse ensino se manifesta nos resultados. Dessa forma, o professor assume o papel de técnico que deve aprender e dominar aplicações desse conhecimento científico, advindos de investigações científicas precedentes (GONÇALVES; $\quad$ FERNANDES, 2010; SCHNETZLER, 2000).

Sendo assim, esse modelo reforça o isolamento de profissionais envolvidos no processo educativo, e acaba por não conseguir dar conta de características intrínsecas da escola, como sua complexidade, incerteza, instabilidade, singularidade e conflito de valores. Sem dizer que esse tipo de perspectiva acaba por não permitir ao professor colocar em evidência sua criatividade, flexibilidade em adaptar-se às características de cada situação a ser enfrentada pela atividade docente.

$\mathrm{Na}$ busca por alternativas de mudanças na formação de professores, tentativas de transformações têm ocorrido na Universidade de Brasília (UnB), que tem procurado estabelecer a sua identidade como curso de licenciatura, desde a concepção das disciplinas de conteúdo de química até as disciplinas específicas de formação pedagógica. O curso tem sido reconstruído em sucessivas reformas curriculares, sempre buscando manter e ratificar essa identidade (GAUCHE et al., 2008).

No projeto político pedagógico do curso de Licenciatura em Química da UnB, são feitas várias propostas curriculares, tais como: direcionamento das disciplinas para a formação profissional docente, isto é, fazer com que todas as disciplinas do currículo estejam comprometidas com a formação do professor; consolidação das disciplinas vinculadas à área de Pesquisa em Ensino de Química; a materialização de estágios em Ensino de Química referentes à prática docente e reflexões teórico-metodológicas estabelecidas nos trabalhos de Conclusão de Curso - TCC (GAUCHE et al., 2008).

Essas necessidades por alternativas de reestruturação são também fomentadas pela nova legislação que exige 400 horas de estágio e mais 400 horas de práticas pedagógicas.

As novas legislações (BRASIL, 2002a, 2002b), convergentes aos pressupostos e fundamentos teóricos de uma desejável formação de professores, determinam importantes normas a serem acolhidas por tais cursos. Dentre estas, pode ser citada a carga horária mínima de 2800 horas dos cursos de licenciatura, que devem ser assim, distribuída: 1800 horas para conteúdos de natureza científico-cultural; 400 horas para estágio supervisionado como componente curricular; 400 horas para prática de ensino como componente curricular e 200 horas para atividades acadêmicocientífico-culturais (BRASIL, 2002a).

Com relação aos conteúdos de natureza científico-cultural, espera-se que este contemple, 
tanto a formação do químico, como proposto pelas Diretrizes Curriculares, quanto à formação do professor, promovendo conhecimentos pedagógicos essenciais. Já as $200 \mathrm{~h}$ de atividades acadêmico-científico-culturais têm por finalidade enriquecer a formação do professor estimulando o licenciando a participar de atividades de cunho cultural, científico e acadêmico.

Em relação às horas destinadas às práticas de ensino, estas não devem mais ser concentradas no fim do curso, mas durante toda a formação docente. Devem permear a formação desde o início do curso, estando presente em toda a grade curricular, no interior das áreas ou disciplinas de provimento dos componentes curriculares, que não somente nas disciplinas pedagógicas, possibilitando ao licenciando colocar em prática atividades ou situações de ensino que visem transformar o conhecimento científico em conhecimento escolar. Já para o estágio supervisionado, prevêse sua realização em escola básica a partir do início da metade do curso. Nessas atividades os licenciados devem assumir o papel de professor, participando de atividades que abarquem todos os aspectos do ambiente escolar.

De acordo com (CARVALHO, 1987, p. 3), o "estágio supervisionado deve ser uma das atividades - sem dúvida alguma, a principal dentro de um curso de Prática de Ensino". O que autora pretende com esta frase é destacar que para a formação de um bom professor, necessita-se tanto das aulas na Faculdade como dos estágios, pois sem estes últimos, os alunos ficariam sem poder praticar o ensinar em condições normais de sala de aula. E também como afirmam Silva e Schnetzler (2008, p. 2175),

[...] o estágio supervisionado se constitui em espaço privilegiado de interface da formação teórica com a vivência profissional. Tal interface teoria-prática compõe-se de uma interação constante entre o saber e o fazer, entre conhecimentos acadêmicos disciplinares e o enfrentamento de problemas decorrentes da vivência de situações próprias do cotidiano escolar.

Nos currículos das licenciaturas a realização dos estágios de observação e o de regência de aulas, são obrigatórios, conferindo as licenciaturas um diferencial em relação aos cursos de bacharelado.

As disciplinas que tradicionalmente se destinam a orientar e supervisionar os mencionados estágios são denominadas de "Estágio Supervisionado", que como uma disciplina comum, serve como uma "prestação de contas" oficial das atividades de estágio, tanto o de observação, quanto o de regência de aulas, e esta prestação, em geral, se faz por meio da apresentação por parte do licenciando, de um relatório.

A observação, como processo criativo, pode servir como instrumento relevante para oferecer dados que possam ser utilizados em uma posterior análise. A finalidade de empregar a observação e examinar a situação real do ensino e aprendizagem no dia a dia de uma sala de aula, nas instâncias educacionais, apresenta suas vantagens. Pois, ao fazer suas observações, os estagiários podem ao mesmo tempo em que se deparam com conflitos, propor novas estratégias gerando reflexões que tem por objetivo contribuir na sua formação como um profissional reflexivo, isto é, professores com iniciativa para participar nas discussões curriculares, bem como nas reformas educacionais e que apresentem coerência nos confrontos que encontrarão no ambiente escolar que as vezes se manifestam de forma caótica (UTSUMI, 2006; CRUZ, 2011).

Neste artigo, será discutido o relatório de observação que contém as narrativas realizadas pelos estagiários, como fonte de informações da prática pedagógica de professores de química e como instrumento sinalizador de formação de futuros professores, ressaltando, a já comentada importância de se buscar uma reestruturação, bem como um "novo olhar" para os cursos de licenciatura. 


\section{Metodologia}

Na disciplina de Prática de Ensino e Estágio Supervisionado II, ofertada no $3^{\circ}$ ano do curso de Licenciatura em Química da Universidade em questão, além de quatro aulas semanais teóricas nas quais se discute sobre fundamentos da prática educativa, outras quatro horas da disciplina, são destinadas à realização do Estágio de Observação.

Antecedendo a ida dos estagiários às escolas, foram discutidos nas aulas de Prática de Ensino e Estágio Supervisionado II, os objetivos do estágio e em seguida os procedimentos para a realização do estágio supervisionado. Quanto aos procedimentos o professor orientador entregou aos estagiários um roteiro para monitorar as observações, com alguns tópicos a serem seguidos. Este roteiro tem por finalidade apenas fazer com que o estagiário, aluno que ainda é, focalize aspectos que ele não esteja acostumado a ver.

Esse roteiro não é único, cabe a cada um dos orientadores de estágio, decidir por algum modelo já utilizado ou elaborar o seu, a fim de que o mesmo atenda as necessidades específicas de formação da região em que se trabalha. Ter o roteiro em mãos não significa limitar-se em responder e refletir sobre o que ali está sendo pedido pode-se ir além, "enxergar" outras possibilidades, sempre em busca de compartilhar experiências, fazer análises, para que assim possam advir reflexões. Além disso, vale destacar que o roteiro, não tem por intenção "ocultar" certos acontecimentos, nem "iluminar" outros, como o próprio nome sugere trata-se de um encaminhamento.

Os dois tópicos que nortearam os relatórios aqui analisados são descritos a seguir.

No primeiro tópico denominado de $A$ Estrutura Escolar, refere-se à composição geral da escola, constituída pelos subitens; nome da escola, endereço completo, telefone, direção, supervisão de ensino, horário de funcionamento, níveis de ensino, histórico da escola, características físicas e arquitetônicas da escola e relação escola/sociedade. Para essa primeira etapa, foi explicado aos estagiários que este tópico consiste em conhecer um pouco mais sobre a escola, sua localização, as pessoas que a constituem, um pouco sobre a sua história, sua estrutura física, os níveis de ensino atendidos, número de turmas, o seu projeto político pedagógico (PPP), como se dá o binômio escola/sociedade e que tipos de projetos sociais desenvolvem.

O segundo tópico abordado nos relatórios foi constituído pelo tema: O Ensino de Química. Este tópico continha itens relacionados às observações das aulas de química. Foi explicado aos estagiários que com relação às aulas assistidas eles deveriam explanar sobre a metodologia adotada pelo professor, a relação professor/aluno, os conteúdos específicos, ao currículo e as avaliações enfim, as articulações que são essenciais na prática educativa.

Foi solicitado que todos estes dados, ao serem transcritos para o relatório, não fossem apenas descritivos, mas também com reflexões relacionadas às teorias estudadas, isto é, aquelas que propõem modelos pautados na racionalidade prática (ZEICHNER, 1993; GABINI; DINIZ, 2009), em que a aula é objeto de reflexão e de investigação por parte do professor.

Para este estudo foram analisados doze relatórios de observação de alunos do curso de Licenciatura, referentes ao ano de 2008. Estes relatórios constituem o número de alunos que foram orientados por uma das autoras do artigo. Vale ressaltar que após a leitura e análise destes relatórios, nota-se a criatividade e a espontaneidade demonstrada por alguns alunos em narrar os episódios observados, contrapondo-se a inibição de outros que como num relato ingênuo respondem apenas o mínimo necessário, como num "jogo" de verdadeiro ou falso. Considerando estas características, algumas narrativas foram selecionadas para serem discutidas, levando em consideração os depoimentos dos alunos com relação aos tópicos solicitados. 


\section{Resultados e Discussão}

Dos doze relatórios, descrevendo sobre o estágio de observação, todos foram realizados em escolas públicas da nossa comunidade - município de Londrina, Paraná e para a maioria dos licenciandos, esses estágios são de fato o primeiro contato e experiência na área do magistério e da sua dinâmica no âmbito escolar. Sendo assim, julgamos importante salientar que alguns desses relatos se apresentaram com certa carência de reflexão, muitas vezes se limitando a descrições curtas e isoladas, descontextualizadas e até por vezes repetitivas.

Com relação à estrutura escolar, todos os estagiários citam, como mencionado no roteiro, o nome da escola, seu endereço, horário de funcionamento, nome da equipe administrativa, totais de turmas matriculadas do referido ano e níveis de ensino.

Com relação ao histórico da escola, os estagiários narram sobre sua fundação e suas primeiras turmas e quanto as características físicas e arquitetônicas, relatam a quantidade das salas de aulas, salas de vídeo, salas de leitura, salas de apoio, ou seja, ambientes destinados ao espaço de ensino e aprendizagem entre outros ambientes presentes na escola como os laboratórios de ciência e de informática, quadras desportivas, bibliotecas, sala da direção, secretaria, cozinha, pátio, sanitários e cantina.

Alguns estagiários enquanto narram às quantidades de ambientes existentes, procuram retratar características que os qualificam, como a narrativa do estagiário E1:

O laboratório é amplo com duas bancadas distribuidas simetricamente no seu espaço com capacidade de comportar uma turma inteira de uma só vez, além de quadro de giz e pias para lavagem dos equipamentos. Possui alguns reagentes comuns como sais, alguns ácidos e bases. As vidrarias vão desde tubos de ensaio a buretas e provetas, possui basicamente todas as vidrarias básicas a uma aula de laboratório.
$\mathrm{Na}$ descrição desse laboratório, o estagiário enfatiza o espaço, os equipamentos necessários para a realização de uma aula prática de química, reagentes e vidrarias, no entanto, dando continuidade à descrição percebe-se por parte deste estagiário uma preocupação sobre a pouca utilização deste ambiente, conforme a narrativa

O laboratório possui um ótimo potencial para as aulas práticas, pois seu espaço é grande e confortável, porém sua situação é de extremo abandono, pois possui várias vidrarias sujas com resto de reagentes $e$ quebradas em cima das bancadas e pias, os armários onde estão guardados os reagentes e vidrarias estão empoeirados sem identificação e mal organizados. É realmente uma pena um laboratório com tanto para ser explorado pelos professores e alunos estando em situação de abandono.

Fica evidente a preocupação do estagiário quanto a não utilização do laboratório, que está equipado para ser usado. $\mathrm{O}$ estagiário aprende nas disciplinas específicas de ensino durante o curso a importância da relação teoria-prática, e o quanto essa relação é significativa para a aprendizagem, porém enfatizando sempre que a relação teoriaprática não deve ser tratada simplesmente como a prática sendo comprovação da teoria ou vice versa (ZANON; SILVA, 2000).

Foram selecionadas algumas narrativas sobre a biblioteca das escolas, como a do estagiário E2:

Possui uma ótima infra-estrutura, desde cadeiras e mesas conservadas ao acervo de livros que conta com muitos livros de literatura brasileira com nomes como Carlos Drumond de Andrade, Guimarães Rosa, João Cabral de Melo Neto, Machado de Assis, Clarice Lispector entre outros. A seção de dicionários é vasta e moderna, com direito a coleção completa de enciclopédias e atlas geográficos. A seção de livros de química não é diferente, o acervo $e ́$ grande e diversificado. $O$ ambiente é bem agradável para a prática de estudo. 
E a narrativa de outro estagiário E3:

A biblioteca tem bastante mesa para os alunos fazerem trabalhos e uma vasta variedade de livros, não muitos em quantidades mas muitos em opções. Os livros técnicos já são em maior quantidade, os de química temos desde básicos de ensino médio até alguns universitários de conteúdo mais especifico, apesar de serem poucos os alunos que utilizam. A biblioteca dos alunos fica fora dos blocos de sala de aula, se encontrando no pátio para que os alunos tenham maior facilidade de acesso no intervalo.

As narrativas dos estagiários com relação à biblioteca mostraram a preocupação em olhar as condições da mesma, a quantidade de livros, em especial os relacionados à química e se os alunos o utilizam ou não. Embora os relatos não contenham dados quantitativos, percebe-se nas descrições, a vasta extensão de livros presentes, bem como a preocupação das escolas quanto a localização da biblioteca, facilitando o acesso para os alunos. Uma preocupação, por sinal, bem notada por um dos estagiários.

Quanto às salas de aula, foram selecionados os depoimentos de dois estagiários E1 e E4, respectivamente:

Estão em bom estado, suas carteiras e cadeiras são apropriadas para oportunizar aos alunos conforto para assistirem as aulas, os quadros também se encontram em boas condições, ventiladores e televisão estão presentes. As paredes em geral não estão rabiscadas e em algumas salas são usadas para a exposição dos trabalhos realizados pelos alunos" e "O colégio possui 38 salas de aula com 40 carteiras em cada sala, todas em estados adequados para a aula, tendo em média 30 a 35 alunos por sala. As salas possuem ainda ventiladores, armário para o professor e televisor.

Nestas narrativas percebe-se um olhar dos estagiários somente para os aspectos físicos das salas de aula, visualizando-as vazias, sem a presença dos alunos e professores. E quanto a sala dos professores, o mesmo padrão de depoimento foi identificado.

Os relatos acima descritos, relacionados à estrutura escolar, apresentam sua importância, a nosso ver, justamente na busca pela familiarização com o futuro ambiente profissional, seu funcionamento, sua composição, conhecendo um pouco mais sobre os vários espaços existentes e que constituem a instituição escolar.

Da leitura feita do PPP da escola, os alunos o descrevem tal como exposto no documento sobre os objetivos gerais do colégio como, por exemplo, a narrativa de um dos estagiários E7: "Formar cidadãos responsáveis, capazes e independentes que conheçam e exerçam seus direitos e deveres, sendo críticos e participativos na vida sóciopolítico-econômica, possibilitando uma sociedade melhor".

Os estagiários retiraram frases prontas do documento e não fizeram comentário a respeito. Talvez, até mesmo porque para os próprios professores, este documento seja um pouco desconhecido, elaborado de forma individual, normalmente por alguns membros, acabam não sendo de livre acesso, como confirmado pelo relato de outro estagiário E5:

É uma pena que o PPP do colégio seja protegido a sete chaves, existem muitas regras para se ter acesso a ele. Você tem que dizer qual a sua intenção ao olhá-lo, tem que ir para a biblioteca estudá-lo e, para que sejam feitas cópias, é necessário fazer um pedido à pedagoga, ela telefona para o xérox e informa às páginas que você pode tirar cópias.

O segundo tópico, relacionado ao ensino de química, foi analisado.

Para uma melhor discussão deste item seguem algumas narrativas dos estagiários, quanto a metodologia adotada pelos professores observados.

Narrativa 1: O professor que acompanhei durante a observação é uma pessoa muito experiente em sala de aula, pois são 41 anos lecionando. Suas aulas são organizadas de 
acordo com o planejamento inicial da disciplina com apoio de alguns livros por ele adotado, que ele utiliza em sala para passar exercícios para os alunos. As aulas são teóricas e o conteúdo é passado somente no quadro. A contextualização dos conteúdos apresentados é feita de forma tímida e imperceptivel para os alunos, visto que o professor prioriza a resolução de exercícios.

Neste relato percebe-se as angústias sentidas pelo estagiário, com relação à postura do professor, embora os seus 41 anos de profissão the forneçam experiência e segurança no desenvolver das aulas, suas aulas são definidas pelo estagiário como meramente expositivas, o livro didático é utilizado somente para a resolução de exercícios em detrimento dos conceitos nele contido e carência da contextualização. Estas observações trazidas pelo estagiário mostram que ainda o ensino da química tem acontecido com a ausência de interação entre professor-aluno que não favorece o diálogo na construção do conhecimento. Esta narrativa nos leva a crer que a formação deste professor foi fundamentada no modelo de racionalidade técnica, isto é com uma visão simplista para a prática docente e que concebe o professor como não produtor de saberes docentes (PÉREZ GÓMEZ, 1992). Neste modelo, este professor é considerando como simples executor de idéias pensadas por outros.

Seguem outras narrativas:

Narrativa 2: A professora utiliza os livros adotados pelo governo para organizar suas aulas, e outros livros complementares. As aulas seguem o estilo tradicional, sempre expositivas, algumas vezes, nos assuntos mais recentes, ela utiliza textos e figuras, que tira cópia e disponibiliza a todos os alunos. A professora não utiliza material de apoio durante as aulas, passando toda a matéria no quadro.

Narrativa 3: No planejamento feito pela professora está estabelecido, em suas metodologias, que a cada conteúdo ministrado é fechado com uma aula prática em laboratório, porém isso não ocorre devido à insuficiência na carga horária da matéria.
A narrativa 2 é importante porque nos faz refletir sobre a declaração de muitos professores de que 2 aulas semanais de química são insuficientes para a grade curricular, no entanto, verifica-se que muitos professores do ensino médio, gastam grande parte da aula, escrevendo o conteúdo no quadro, enquanto os alunos copiam. Isto mostra a prioridade por parte dos professores quanto à quantidade de conteúdo a ser dada, enquanto poderiam utilizar este tempo dialogando os conceitos com os alunos de forma que os mesmos participassem ativamente na sua construção. Além disso, poderiam situar a química em um contexto social, político, econômico e tecnológico, pois a escola, mais especificamente as aulas de química não podem manter-se alheia a estes contextos. A narrativa 3 vem reforçar a idéia de muitos professores do ensino médio, de que os conceitos só são aprendidos de forma expositiva e em sala de aula, como se o laboratório não fosse um espaço para gerar a aprendizagem, isto é, uma valorização acentuada das aulas expositivas e memorísticas.

Podem ser situações como estas que provoquem um comportamento desatento por parte dos alunos, como demonstrado nas narrativas a seguir.

Narrativa 4: São na grande maioria moradores do bairro, frente aos conteúdos de química ensinados, muitos mostram bloqueios com a disciplina, ficando na maioria das vezes apenas sentados em suas cadeiras ouvindo o professor falar de uma coisa que eles não entendem.

Narrativa 5: São bem alvoroçados, dispersos, com uma grande falta de interesse pela matéria, isso tudo devido à falta de motivação por parte da professora.

As narrativas mostram a existência de alunos nos dois extremos de comportamento, de um lado os alunos indiferentes com relação à aula e aos conteúdos de química e de outro lado a presença da indisciplina. Na nossa realidade estes comportamentos de certa forma são comuns de serem observados nas salas de aula e embora opostos, são decorrentes da ausência de ensinar a química dentro 
de uma concepção que destaque o papel social da mesma, por meio de uma contextualização social, política, filosófica, histórica, econômica, ambiental e religiosa (CHASSOT, 1995) e da problemática da formação do professor de química, tradicionalmente centrada no modelo da racionalidade técnica, com ênfase no domínio do conteúdo químico e a adoção de algumas técnicas pedagógicas (CACHAPUZ, 2000; SANTOS; SCHNETZLER 2003). Entretanto, felizmente existe exceção como mostra a narrativa 6.

Narrativa 6: Nas aulas observadas pude notar que, a professora procura sempre contextualizar o conteúdo. Na maior parte de suas aulas procura relacionar o conteúdo tratado no livro didático com o momento vivido pela sociedade.

Algumas narrativas sobre avaliação foram selecionadas e transcritas a seguir.

Narrativa 7: As avaliações se deram por meio de uma avaliação bimestral valendo 30 pontos e várias atividades realizadas em sala e fora da sala valendo entre 20 e 30 pontos, algumas foram em duplas e a maioria individual.

Narrativa 8: Com relação à forma de avaliação o professor aplica provas periódicas, valendo 40 a 50 pontos. Ao final de cada avaliação se houver tempo o professor resolve a prova no quadro. O professor pontua os jovens também com pesquisas realizadas por eles e resolução de exercícios no quadro.

Narrativa 9: Para avaliar o aprendizado dos alunos, são feitas duas provas com questões discursivas e de múltipla escolha com o valor de 40 pontos cada, mais listas de exercícios como valor de 20 pontos. Se o aluno não atinge a média, que é de 60 pontos, é aplicada uma avaliação de recuperação que substitui a nota das provas feitas anteriormente.

Com relação às avaliações, os estagiários apenas descrevem o que é feito, descrevendo de que forma o professor regente atribui notas aos alunos, nesta parte, nada comentam sobre os critérios utilizados nem sobre a eficácia dos instrumentos avaliativos.
Por meio das narrativas e das reflexões advindas das mesmas vemos a importância dos estágios de observação, é ali, presente na escola e na sala de aula que o estagiário vai se constituindo como futuro profissional e refletindo a respeito do significado de ser professor.

\section{Conclusão}

Nas análises desses relatórios de observação vemos a importância e a necessidade de que ao mesmo tempo em que aconteçam esses estágios, ocorram também na universidade, discussões acerca do mesmo.

Muito mais do que simplesmente a entrega do relatório final, vemos a necessidade por parte do professor-supervisor de proporcionar momentos de leitura e reflexões sobre o que está sendo observado, como os estagiários estão compreendendo o que observam, quais suas reflexões e futuras ações, fazendo deste estágio um momento de pesquisa sobre a prática docente.

Conforme diz Abdalla (2006, p. 45) "pensamos que seja necessário compartilhar experiências pessoais e profissionais: a prática, as ações e condições de trabalho. Pois, quando analisamos as situações, juntos com os outros, tomamos consciência de nossas intenções e ações na busca de inovações".

A necessidade de mudanças curriculares tornase indispensável, visando à constituição de um currículo de licenciatura que garanta a identidade do curso de formação de professores de Química, de forma a integrar a formação teórico-prática com a especificidade do trabalho docente e com a realidade do sistema educacional.

Acreditamos que precisamos voltar nossos olhares na formação de professores, neste caso específico na formação de professores de química, se o que queremos dos futuros professores esteja relacionado ao verbo descobrir, ou reinventar através da redescoberta, e será preciso curvar-se 
ante tais necessidades se o que se pretende, é moldar indivíduos capazes de produzir ou de criar, e não apenas repetir.

\section{Referências}

ABDALLA, M. de F. B. O senso prático de ser e estar na profissão. São Paulo: Cortez, 2006.

BRASIL. Ministério da Educação. Resolução $C N E / C P$. $n^{o}$. 01/2002. 2002a. Disponível em: <http://portal.mec. gov.br/cne/arquivos/pdf/rcp01_02.pdf $>$. Acesso em: 27 jul.2010.

BRASIL. Ministério da Educação. Resolução $C N E / C P$. $n^{o}$. 02/2002. 2002b. Disponível em: <http://portal.mec. gov.br/cne/arquivos/pdf/CP022002.pdf >. Acesso em: 27 jul.2010.

CACHAPUZ, A. F (Org.). Formação de professores/ ciências. Porto: CEEC, 2000.

CANDAU, V. M. F. (Coord.). Novos rumos da licenciatura. Brasília: INEP, 1987.

CARVAlHO, A. M. P. de. Prática de ensino: os estágios na formação do professor. 2. ed. São Paulo: Livraria Pioneira, 1987.

CARVALHO, A. M. P. de; GIL-PÉREZ, D. Formação de professores de Ciências: tendências e inovações. 7. ed. São Paulo: Cortez, 2003.

CHASSOT. A. Para que(m) é útil o ensino? Canoas: Ulbra, 1995.

CRUZ, T. P. O olhar do professor reflexivo sobre o fracasso escolar. Revista de Educação, Linguagem e Literatura da UEG-Inhumas. Goiânia, v. 3, n. 1, p. 5162, 2011.

FRANCISCO JUNIOR, W. E.; PETERNELE, W. S.; YAMASHITA, M. A formação de professores de química no estado de Rondônia: necessidades e apontamentos. Química Nova na Escola, São Paulo, n. 2, p. 113-122, 2009.

GABINI, W. S.; DINIZ, R. E. S. Os professores de química e o uso do computador em sala de aula: discussão de um processo de formação continuada. Ciência \& Educação, Bauru, v. 15, n. 2, p. 343-358, 2009.

GALIAZZI, M. do C. Educar pela pesquisa: ambiente de formação de professores de ciências. Ijuí: Unijuí, 2003.

GAUCHE, R.; SILVA, R. da; BAPTISTA, J. de A.; SANTOS, W. L. P. dos; MÓL, G. de S.; MACHADO, P. F. L. Formação de professores de química: concepções e proposições. Química Nova na Escola, São Paulo, n. 27, p. 26-29, 2008.

GONÇALVES, F. P.; FERNANDES, C. S. Narrativas acerca da prática de ensino de química: um diálogo na formação inicial de professores. Química Nova na Escola, São Paulo, n. 2, p. 120-127, 2010.

LORENCINI, Á. As demandas formativas do professor de ciências. In: CAINELLI, M. R.; SILVA, I. F. (Org.) O estágio na licenciatura: a formação de professores e a experiência interdisciplinar na Universidade Estadual de Londrina. Londrina: UEL, 2009. p. 21-41.

MALDANER, O. A. A formação inicial e continuada de professores de química. Ijuí: Unijuí, 2000.

PÉREZ GÓMEZ, A. Las funciones sociales de la escuela: de la reproducción a la reconstrucción crítica del conocimiento y la experiencia. In: GIMENO SACRISTÁN, J.; PÉREZ GÓMEZ, A. Compreender y transformar la escuela. Madrid, Morata, 1992. p. 398429.

SANTOS, W.; SCHNETZLER, R. P. Educação em química: compromisso com a cidadania. 3. ed. Ijuí: Unijuí, 2003.

SCHNETZLER, R. P. O professor de ciências: problemas e tendências de sua formação. In: SCHNETZLER, R. P.; ARAGÃO, R. M. R. (Org.). Ensino de ciências: fundamentos e abordagens. Campinas: UNIMEP, 2000. p. 12-21.

SILVA, R. M. G.; SCHNETZLER, R. P. Concepções e ações de formadores de professores de Química sobre o estágio supervisionado: propostas brasileiras e portuguesas. Química Nova, São Paulo, v. 31, n. 8, p. 2174-2183, 2008.

UTSUMI, L. M. S. É possível formar professores reflexivos que possam situar-se em níveis da realidade escolar? Considerações acerca da formação de professores na construção de uma escola reflexiva. Academos: revista eletrônica da FIA, São Paulo, v. 2, n. 2, p. 69-77, 2006.

ZANON, L. B.; SILVA, L. H. A. A experimentação no ensino de ciências. In: SCHNETZLER, R. P.; ARAGÃO, R. M. R. (Org.). Ensino de ciências: fundamentos e abordagens. Campinas: CAPES, 2000. p. 154-181.

ZEICHNER, K. M. A formação reflexiva de professores: idéias e práticas. Lisboa: Educa, 1993.

Recebido em 15 Abril 2011-Received on April 15, 2011.

Aceito em 8 Agosto, 2011 - Accepted on August 8, 2011. 
Broietti, F. C. D.; Barreto, S. R. G. 